\title{
EDITORIAL
}

For reprint orders, please contact: reprints@futuremedicine.com

\section{The needs of ethnic minority elderly individuals with dementia}

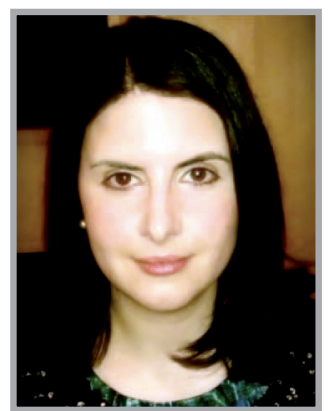

Sofia Zarate

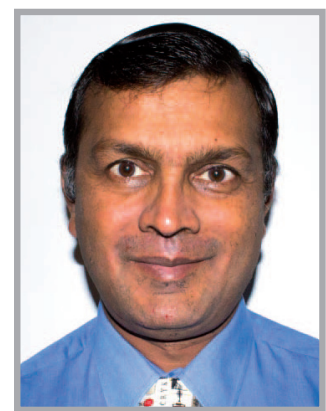

Ajit Shah*2 “...black and minority ethnic elders are poorly represented in old age psychiatry services in secondary care, and this is despite them having high

general practice

consultation rates."

\section{Escudero ${ }^{1}$}

Dementia is a progressive illness that has a devastating effect, not only on the patient, but also on the extended family. Most dementias have a poor prognosis, with survival of between 5 and 8 years from diagnosis.

Life expectancy in the UK continues to rise. The two most common mental health disorders affecting the elderly are dementia and depression [1]. The prevalence of dementia doubles every 5.1 years after the age of 60 years $[2,3]$. Thus, the proportion of those with dementia among the elderly will also increase. Therefore, it is vital that the assessment, diagnosis and treatment of dementia is prompt and comprehensive. However, this may not always be the case with dementia sufferers from ethnic minority groups.

\section{Ethnic minority demography}

In 2001, the population census for England and Wales revealed that the proportion of black and minority ethnic (BME) individuals over the age of 65 years had progressively increased from $1 \%$ in 1981, to $3 \%$ in 1991 and $8.2 \%$ in 2001 [1]. These figures, however, contrast with
$17 \%$ of the indigenous UK population over the age of 65 years. Moreover, $7.1 \%$ of all elderly individuals in England and Wales were from BME groups in the same 2001 census and the total number of elderly individuals from all BME groups combined was 531,909. Data from the 2011 census are likely to illustrate a further increase in these figures. The change in population demography currently observed in England and Wales has also been observed in other countries, including the USA and Australia [4]. Yet, despite the clear and obvious demographic changes that are taking place within the UK, there are only a few population studies that look at mental health disorders among elderly BME individuals in the UK and reflect this change.

\section{Epidemiology of dementia in BME older individuals}

Livingston and colleagues conducted a population-based prevalence study of dementia in elderly individuals born outside the UK [5]. The prevalence of dementia among those born in Ireland, Cyprus, Africa and the Caribbean was 10, 3.6, 11.3 and $17 \%$, respectively. Furthermore, risk "...it is encouraging that there is clear recognition ... that black and minority ethnic elders face particular challenges and are especially vulnerable to exclusion, marginalization and inequality in

mental health promotion and mental health service access." 
factors predicting dementia included age, residing in a residential home, years of education and being African or Caribbean.

McCracken and colleagues conducted a population study of dementia among ethnic minority elders in Liverpool [6]. The prevalence of dementia in English-speaking individuals was: $8 \%$ black Africans; $8 \%$ black Caribbeans; 2\% black others; 5\% Chinese; and 9\% Asians. The prevalence in black Africans and Chinese who did not speak English was 27 and 21\%, respectively. These higher figures among non-English speakers may have been an artifact of communication and translation difficulties [6]. Two other studies among older Gujaratis and those of Indian subcontinent origin in Leicester and Bradford, respectively, have reported similar findings $[7,8]$.

A number of studies involving indigenous elderly individuals reported a prevalence of dementia to be similar or lower than the figures in the above ethnic minority groups [9]. Thus, the prevalence of dementia among elders from different BME groups in the UK is similar or higher when compared with indigenous elders.

\section{Burden of dementia}

A study conducted by Kings College (London, UK) and the London School of Economics (London, UK) estimated that the absolute number of cases of dementia within the BME population in the UK was 11,860 in 2004 [101]. Another study estimated the absolute number of cases of dementia in the UK to be between 7270 and 10,786 and of depression to be between 33,559 and 52,980 among BME older individuals from all ethnic minority groups combined [1]. Yet, despite the clear increase in psychiatric morbidity within this group, the prevalence of BME individuals in contact with secondary specialist services continues to remain low [10,11]. These findings are not exclusive to the UK and have also been observed in Australia [12].

\section{Pathways to care}

In order for patients to be seen in specialist secondary care services, they must pass through several stages of clinical care. The illness must first manifest itself and usually this occurs in the community. If patients (or their relatives) are able to identify symptoms, the next step is usually to go and see their general practitioner (GP). In the past, it has been erroneously believed that BME individuals had little or no access to primary healthcare services or that they were not aware of how to access primary care services, yet this is simply not the case [4].

Older individuals and their relatives from several different BME groups, including those from the African Caribbean, Asian, Chinese and Vietnamese groups, were well aware of services that were provided by their GPs $[13,14]$. In addition to this BME elders also have high general practice consultation rates [10]. For example, $70 \%$ of Gujarati elders in Leicester had consulted their GP in the preceding month [10]. Nevertheless, the prevalence of BME elders with dementia in contact with specialist services is generally low $[10,11]$.

What are the potential reasons for $\mathrm{BME}$ elders being poorly represented in secondary care despite comparable prevalence of dementia and high GP consultation rates? Several explanations have been offered to explain the paradox between frequent consultations in primary care and the low prevalence rates in secondary care. First, diagnosis of dementia is contingent upon the presence of functional impairment, but there may be different thresholds for functional impairment in different cultures depending on the social roles and cognitive demands placed on the elderly individual. Second, patients and family members may be unfamiliar with symptoms of dementia $[15,16]$ as traditionally few BME elderly individuals reach old age [17]. Moreover, symptoms of dementia may simply be dismissed as a function of old age [4]. Third, this may be further exacerbated, if neither the patient or their family are able to communicate symptoms of dementia to the GP, owing to a lack of appropriate vocabulary or fluency in English [18]. Fourth, patients and families may simply not know how to access specialist help or may simply believe that available services are inadequate and culturally insensitive $[10,19]$. In addition, they may have previously had poor experience of services. Finally, it may simply be the case that patients may wish to use alternative medicine and consult with traditional healers rather than GPs for their mental illness.

In addition, there is a paucity of studies examining clinical presentation, diagnostic features and the natural history of dementia in BME older individuals [20,21], and individual GPs may see relatively few BME elderly individuals with mental illness. Therefore, GPs may lack the clinical experience, expertise and diagnostic skills needed for BME elderly individuals, and psychiatrists also experience this difficulty [18].

The basis of assessment and screening for the diagnosis of dementia is based on the principles 
of history taking, and mental state and physical examination, coupled with specialist investigations. The existing screening instruments for dementia have been developed in several languages commonly spoken by BME older individuals. However, translated versions of the screening/assessment tools are difficult to directly administer unless the clinician is fluent in the relevant language. Moreover, the clinician cannot solely rely on the interpreter to accurately administer the instrument because the clinician will not be able to ascertain the accuracy of the translation, and this has not been formally evaluated.

GPs may identify dementia within this group; however, they may choose to not refer the patient on to specialist secondary care. As mentioned earlier, the presentation of a functional impairment is required to meet the criteria for dementia; however, patients can sometimes present with troublesome behavioral and psychological signs and symptoms of dementia. If the patient lacks these troublesome symptoms, the GP may consider referral to secondary care unnecessary [4]. Ironically, however, behavioral and psychological symptoms of dementia, which often lead to clinical presentations, have been poorly studied among ethnic minority elderly individuals, although studies are now emerging [20].

The GP may feel that he/she is better able to communicate with the patient, particularly if they share the same ethnic background; up to $70 \%$ of Asians in the UK are registered with Asian GPs [22]. In addition, the patient or the family may object to a proposed referral to secondary care by the GP. Reasons for this include: the belief that nothing can be done; the belief that ethnically sensitive services are unavailable; and patients and relatives may have had previous poor experiences of secondary care and social services [4].

\section{Policy issues}

Over the last decade, the difficulties experienced by BME groups has become an important national priority in the UK and this has resulted in the publication of a number of governmental reports, guidelines and policies. The most recent publication for dementia is the National Dementia Strategy for England, which has recommended a framework for the management of dementia and paid considerable attention to the importance of these facilities for ethnic minority elders [23]. Nevertheless, documentation on paper and in policy is not the same as implementation in service planning and delivery. The real challenge is to ensure that governmental policies are implemented on an ongoing basis, and that this implementation is monitored and evaluated.

\section{Conclusion}

The demography of the UK has been changing with an increase in the elderly BME populations. These changes, in conjunction with the prevalence of dementia in this group being similar or higher in comparison with the indigenous population, suggest that the absolute number of cases of dementia are likely to increase significantly among BME elders. Yet, despite this obvious need for further specialist care and research, BME elders are poorly represented in old age psychiatry services in secondary care, and this is despite them having high general practice consultation rates. Clearly there are multifactorial obstacles to receiving secondary care. The reconfiguration of mental health services in the UK, in particular that of old age psychiatry, are creating a clear reduction of inpatient beds and community facilities available to the most vulnerable patients; with a move away from specialist services toward a more generalist approach, a working model of an 'ageless service'. If these changes continue to take place, it is possible that over the next decade we will see a worsening of this situation, where the most vulnerable patients who already struggle to receive the care that they need may simply disappear from care settings. Nevertheless, it is encouraging that there is clear recognition in various policy documents that BME elders face particular challenges and are especially vulnerable to exclusion, marginalization and inequality in mental health promotion and mental health service access. Better understanding of the meanings of mental well being and mental ill health given by BME elders, their help-seeking preferences and their perceptions of reasons for poor access to mental health services may better enable implementation of these policies and inform development of future policies.

\section{Financial \& competing interests disclosure}

The authors have no relevant affliations or financial involvement with any organization or entity with a financial interest in or financial conflict with the subject matter or materials discussed in the manuscript. This includes employment, consultancies, honoraria, stock ownership or options, expert testimony, grants or patents received or pending, or royalties.

No writing assistance was utilized in the production of this manuscript.

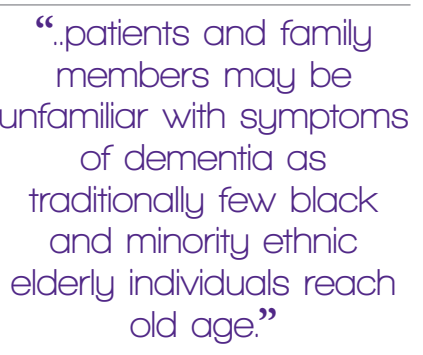

"..patients and family ay be of dementia as traditionally few black and minority ethnic old age." 


\section{References}

1 Shah A. Estimating the absolute number of cases of dementia and depression in the black and minority ethnic elderly population in the UK. Int. J. Migration Health Social Care 4, 4-15 (2008).

2 Jorm AF, Korten AE, Henderson AS. The prevalence of dementia: a quantitative integration of the literature. Acta Scand. Psychiatr. 76, 465-479 (1987).

3 Hofman A, Rocca WA, Brayne C et al. The prevalence of dementia in Europe: a collaborative study of 1980-1990 findings. Int. J. Epidemiol. 20, 736-748 (1991).

4 Shah AK, Lindesay J, Nnatu I. Cross-cultural issues in the assessment of cognitive impairment. In: Dementia. Burns A, O’Brien J, Ames D (Eds). Arnold Hodder, London, UK, 147-164 (2005).

5 Livingston G, Leavey G, Kitchen G et al. Mental health of migrant elders - the Islington study. Br. J. Psychiatry 179, 361-366 (2001).

6 McCracken CFM, Boneham MA, Copeland JRM et al. Prevalence of dementia and depression among elderly people in black and ethnic groups. Br. J. Psychiatry 171, 269-273 (1997).

7 Lindesay J, Jagger, C, Mynik-Szmid A, Sinorwala A, Peet S, Moldena F. The mini-mental state examination (MMSE) in an elderly immigrant Gujarati population in the United Kingdom. Int. J. Geriatr. Psychiatry 12, 1155-1167 (1997)

8 Bhatnagar KS, Frank J. Psychiatric disorders in elderly from the Indian subcontinent living in Bradford. Int. J. Geriatr. Psychiatry 12, 907-912 (1997).

9 Shah AK. The burden of psychiatric disorders in primary care. Int. Rev. Psychiatry 4, 243-250 (1992).

10 Lindesay J, Jagger C, Hibbert MJ et al. Knowledge, uptake and availability of health and social services among Asian Gujarati and white elders. Ethn. Health 2, 59-69 (1997).

11 Shah AK, Dighe-Deo D. Elderly Gujaratis and psychogeriatrics in a London psychogeriatric service. Bull. Int. Psychogeriatr. Assoc. 14, 12-13 (1997).

12 Pollit P. Dementia in old age: an anthropological perspective. Psychol. Med. 26, 1061-1074 (1996).

13 Bhalia A, Blakemore K. Elders of the Minority Ethnic Groups. AFFOR, Birmingham, UK (1981).

14 McCalman JA. The Forgotten People: Carers in Three Minority Commmunities in Southwark. Kings Fund Centre, London, UK (1990).

15 Bowes A, Wilkinson H. 'We didn't know it would get so bad': south Asian experiences of dementia and service response. Health Social Care Comm. 11, 387-396 (2003).

16 Purandare N, Luthra V, Swarbrick C, Burns A. Knowledge of dementia among South Asian (Indian) older people in Manchester, UK. Int. J. Geriatr. Psychiatry 22, 777-781 (2007).

17 Manthorpe J, Hettiaratchy P. Ethnic minority elders in Britain. Int. Rev. Psychiatry 5, 173-180 (1993).
18 Shah AK. Difficulties experienced by a Gujarati psychiatrist in interviewing elderly Gujaratis in Gujarati. Int. J. Geriatr. Psychiatry 14, 1072-1074 (1999).

19 Lawrence V, Samsi K, Banerjee S, Morgan C, Murray J. The experience of dementia across three ethnic groups. Gerontologist 51, 39-50 (2011).

20 Haider I, Shah A. A pilot study of behavioural and psychological signs of dementia in patients of Indian sub-continent origin admitted to a dementia day hospital in the United Kingdom. Int. J. Geriatr. Psychiatry 19 (12), 1195-1204 (2004).

21 Shah AK. Can the recognition of clinical features of mental illness at clinical presentation in ethnic elders be improved? Int. J. Geriatr. Psychiatry 22, 277-282 (2007).

22 Johnson MRD, Cross M, Cardew S. Inner city residents, ethnic minorities and primary health care. Postgrad. Med. J. 59, 664-667 (1983).

23 Department of Health. Living Well with Dementia: a National Dementia Strategy. Department of Health, London, UK (2009).

\section{- Website}

101 Kings College London and London School of Economics. Dementia UK. The Full Report (2004).

www.alzheimers.org.uk/News_and_ Campaigns/Campaigning/PDF/Dementia_ UK_Full_Report.pdf 